\title{
A World Full of Computers: How Did That Happen?
}

\author{
James W. Cortada \\ IBM Institute for Business Value \\ 2917 Irvington Way, Madison, Wisconsin 53713 USA \\ jwcorta@us.ibm.com
}

\begin{abstract}
This paper argues in favor of more national and global histories of computing, describes the author's current research, and presents preliminary findings about the global diffusion of IT with particular emphasis on developments in the pan-Atlantic community of North America and Europe from to 1940s to 2000. The author introduces a new model for dating events in the diffusion of computing.
\end{abstract}

Keywords: European ICT, global diffusion, historical trends, history of computing, Wave One.

\section{Introduction}

At the end of World War II there were probably up to a dozen devices one might call computers. By the early 1950s, almost every country in Western Europe had at least one computer project underway; many had several. By 1960, there were over six thousand systems around the world, and after the diffusion of personal computers in the 1980s, observers counted the number of newly acquired systems in the millions of units per year. By the end of the 1980s, many other machines had computers in them such as automobiles, microwave ovens, early mobile phones, and in the following decade, cameras. Today, there are so many computers in so many places and things that we no longer know actually how many there are. Rather, we measure IT differently. Instead of asking how many computers exist, we want to know how much traffic is flowing through the international fiber-optic cables that carry all the internet traffic_-its volume doubles every eighteen months and just over half of all this internet traffic is made up of videos, while Facebook messages now surpass all the email combined worldwide [1]. To complicate matters, the number of machines-not computers - that have computational components in them attaching to the internet is now increasing so fast that it will not be long before they outnumber the quantity of people using the internet through mobile phones and other human-used computers.

How did all these things happen? How is it there exists so much computing in extensive use throughout the world that we have difficulty tracking the volume involved? Indeed, how did that infusion of technology into human societies happen so quickly? These are not easy questions to answer. The story of computing is highly fragmented; the quantity of sources historians can study too few; and the number of experts available to do the work insufficient to the task. That is why the efforts of computer professionals, computer scientists, historians, economists, librarians and 
archivists in the Nordic countries collaborating in the study of computing's history is so important.

As this conference-and the two previous ones-make very clear, there are collaborative ways to study the subject, thereby expanding the pool of researchers, increasing the availability of information, and enriching discussions about the history of computing. What your activities have indicated so far, along with the research of others in dozens of countries, is that the history of ICT is bigger, more complex, and central to the history of the twentieth century than historians might have thought even as recently as two decades ago. For example, your work to preserve and study the history of Nordic computing and telecommunications established that all countries in this part of Europe played an enormous role in the lives of the region and in the history of modern Europe. We did not know that even as recently as ten years ago. Other countries can learn from what you are doing today.

First, the importance of the subject warrants discussion. It is not enough to say that there are billions of computers around the world. It is more important to look at their use. To be brief, we know that global diffusion of computers is so great that almost the majority of all data now available are in digital forms and will increase in quantity over time. Today, the majority of digital data consists of images, such as video and still photography, and the greatest amount of text is in English with Chinese increasing rapidly its presence. Libraries and publishers are transforming texts of all languages into digital formats, what French historian, Lucien X. Polastron considers a challenge to even such traditional modes of presenting information as the book and the nature - even the existence — of libraries. To him, digitization is placing libraries and all of us "at a historical turning point" [2, p.161]. I think he is correct. IBM's lens-often forecasting how much computer storage customers will buy-confirms the same, with the volume of exabytes of data going from an estimated 500 just two years ago (2008) to over double that amount by the end of $2012 .^{1}$

Second, the software and hardware emerging in support of the use of digital information continues to appear quickly, as it has for the past fifty years with no evidence that the process of new product introductions is slowing down even in difficult economic times. One has only to observe what has happened at any company, such as all the products that have come from Apple just in the past five years, or by type of device, such as the functions available in mobile phones, cameras, and e-book readers. Kindle and iPad are only two of over two dozen such devices. Over twenty vendors have committed publicly in 2010 to introduce newer versions over the next several years.

However, even more important is the fact that consumers and institutional customers of ICT over time have acquired these technologies faster than prior versions. There are many measures of such adoptions; we all have seen charts that show percents of penetration with electricity taking seventy-five years for modern societies to have 100 percent adoption; that 75 percent of the pan-Atlantic community acquired VCRs in thirty years; that nearly 100 percent had television sets in twentyfive years. It took the pan-Atlantic community less than fifteen years to have nearly

\footnotetext{
${ }^{1}$ One exabyte is equal to one quintillion bytes of data, or $1,000,000,000,000,000,000$. In early 2010 the internet's total volume of material amounted to about 22 exabytes. Keep in mind that not all data passes through the internet so there is more than 22 exabytes of digitized information in the world.
} 
half its homes and businesses using PCs, barely a decade for 75 percent of Western Europeans to have mobile phones and over half the population access to the internet. Consumers bought digital television sets sooner than they did PCs, because they had learned how to buy digital devices; they did not hesitate to rid themselves of film for digital photography and are now replacing first generation flat screen TVs. Hence, people and institutions are acquiring digital devices even faster than in the past and in the process are embracing a digital social zeitgeist. The wealthiest economies are doing it the fastest and most extensively, of course. Nevertheless, as the costs of digital technologies shrink as they also come in smaller, hence less expensive, products their affordability spreads. That is one important reason why Africa and China are now the fastest growing markets for mobile phones, which we all know are small computational devices, with smart phones rapidly becoming platforms for "apps," potentially the most important evolution in IT hardware that we might see in this decade.

\section{The Historian's Challenge}

For historians of ICT the challenge is more than just describing the use of computers in earlier decades, when mostly large organizations acquired them. We now need to explain the diffusion of the technology into consumer and industrial goods as well. It is not an exaggeration to say that almost everyone in a developed or developing economy is a user of ICT. Currently over an additional billion people are moving into the middle class for the first time as well. They too are expected to become users of various ICTs, but, also in different ways than others in early-adopter societies. Given that we know enough about the history of computing to realize that we understand too little in a time of great churn, what are the questions historians must now ask of ICT at this time? There are basic questions among many such as:

- What diffused into the world? When? To whom? Where?

- How did that happen? Was the experience the same in each country? If not, what was it? How did they vary? Moreover, the historian's favorite question-Why?

- What were the specific causes of such a diffusion and why so quickly?

- What roles did various factors play such as technological evolutions, cultural, political and historical realities, economics, and government policies and programs?

- Are there common patterns of diffusion? If so, what were they and how did that happen?

Students of the history of ICT need to deal with these fundamental questions for several reasons. First, the diffusion of massive quantities of computing happened and indeed, they were widespread. Second, current business and government leaders need - and want-to understand how "high tech" uses spread and affect societies, economies and their own organizations. Third, as Spanish sociologist Manuel Castells has been reminding us for over three decades, we may all be entering some postindustrial networked information age that potentially could be quite different in form and style from what the world lived in since the start of the First Industrial 
Revolution. Fourth, we need to study ICT because technological diffusion is a subject of great interest to economists, historians, political scientists, public administrators, businesses, technologists, sociologists, philosophers, computer scientists, and engineers with too many of them not understanding what the others are saying, yet each creating a large body of literature on the role, and sometimes the parallel histories of ICT.

After seventy years of using computers, are we not due for some consensus about humankind's experience with ICT? So a fifth reason: historians in many fields of history are now writing world histories to make sense of how humankind has evolved. Since ICT is such a global phenomenon, it too will become part of the global story. So far, no serious attempts have been made by historians to look at the history of ICT globally; at best their work remains narrowly focused on specific applications, industries, devices, types of technology, and user groups. The most broadly conceived take a national perspective, as we saw recently by French historian Pierre MounierKuhn with his book on France [3]. Trans-national comparative studies are few, although recently one of Europe's leading historians of ICT, Denmark's own Lars Heide, published an excellent example [4].

Several problems must be overcome, however. There are, for example, too few historians of ICT, but probably enough experts on telecommunications. Scholars in other fields and archivists are helping these students of technology; as the Swedes are demonstrating, computer pioneers and ICT professionals are also helping. The work being done in Sweden, that of the IT History Society, the Internet Archives, and the Computer Museum in California are examples of projects and initiatives appearing in many countries that help. Another problem mentioned above is that much research is fragmented, but there is progress. Collaborative or multi-national research projects are appearing more frequently by:

- examining classes of technologies such as European software, Asian printing, and American hardware,

- class of user such as those accessing the internet in various countries, and others about programmers, women in IT, and ICT professionals,

- type of application such as supply chains, banking ATMs, mobile phones, and computing in government,

- industry and country such as banking, government, military, France, Finland, Great Britain, and Sweden, and

- time periods such as the 1930s through the 1950s, the 1970s-1980s, and now beginning, the study of the 1990s.

The problem of fragmentation has many causes and manifestations. Among the causes we can list include too little or too much material to examine with too little done so far. There still is insufficient consensus and inadequate clarity about what issues to study since the subject is so new. Archival collections are too few and what exists are scattered about-European historians too frequently have to go to the middle of the United States-Minneapolis, Minnesota-to study Europe's history of ICT! This situation borders on the ridiculous yet is a remediable problem, as Tom Misa showed at the last Nordic history conference with his discussion on the Charles Babbage Institute (CBI) experience [5]. An important problem for trans-national historiography is that one must deal with too many languages to conduct research, not 
to mention the accommodation of cultural considerations. The few historians expert in this subject are also just now beginning to collaborate on projects, with Europeans leading the way now, in part because of EU funding of pan-European initiatives. Yet most historical research still remains too narrowly focused, with an insufficient number of the sort of what one might call "big history" projects that we see in other sub-fields of history. Moreover, as historians are quick to point out, there is insufficient funding and other resources to support their work, although that is beginning to change with the EU helping in Europe and the National Science Foundation in the United States.

\section{A Way Forward}

Each must do what we can to address these problems and seize upon the opportunities. I am currently examining the way ICT spread around the world between 1940 and the end of the century. While I am only just over halfway through the project, there are a number of observations that can be made about the patterns of deployment. I offer these as a small contribution to the field of ICT history. There are four questions to answer in the project.

- In what countries did ICT emerge?

- How did that happen in each country? And in general?

- What were the factors that made diffusion happen?

- What made possible their speed of diffusion? Was it great technology, other influences, or some combination of factors?

These questions are discussed on a country-by-country basis, selecting some but not all nations that extant evidence suggests might provide answers to these queries and that also allows one to generalize about global patterns. These nations include the United States and the largest in Europe, from Great Britain, France, Germany, and Italy to Russia, but also East Germany and some of its immediate Comecon neighbors, and smaller states such as the Netherlands and Sweden to understand better the pan-European and pan-Atlantic experiences. In Asia there is Japan, where computing first began in the region, but also South Korea, Singapore, Taiwan, and, of course, most recently India and China. There are nations in Latin America to examine such as Mexico and Brazil, but also in Africa too, a continent with over fifty countries.

The story is told in roughly chronological order of diffusion, beginning with the United States, next with Western Europe, followed by Eastern Europe, across East Asia, through Latin America, and finally Africa. Many countries are examined that will not be written up in my study, however, such as smaller states or others that reflected patterns of diffusion of neighboring countries that I do describe in detail. Some are left out because of insufficient space in my project, others because of lack of data. I plan to donate all my research notes, records, and books from this project to $\mathrm{CBI}$ as a way of helping future historians continue this sort of historical inquiry. My focus is on technological, economic, political and managerial issues relying on contemporary reports, secondary literature, and archival materials where available and relevant. 
The story line is becoming clear. First, countries with the most extensive and quick starts did it through national investments in information technologies. World War II and the Cold War led to early starts in the United States, United Kingdom and its Commonwealth nations, Sweden, and the Soviet Union with military, then scientific computing, and ultimately civilian applications. Second, the pan-Atlantic community was able to transfer quickly findings and technologies that originated from military applications and projects to civilian products and uses originating in the United States and in other European nations. Communist states generally blocked movement of military ICT into civilian uses. Asian countries began adopting ICT after initial civilian successes in Europe. Third, almost every country in developed and developing economies simultaneously began small experiments in building computers between the late 1940s and early 1950s; the academic literature has not documented many of these, while those in the pan-Atlantic community always received publication. Speed of diffusion was generally a function of the speed of acquisition and the funding amount. The quickest technology transfers occurred in pan-Atlantic nations in the 1950s and 1960s, and in East Asia beginning with the 1970s. American computer vendors, most notably IBM, were the fastest to scale up their work, investments, sales, and infrastructures to support customers. Almost all national ICT champion programs failed to meet their original objectives with the exception of Japan and South Korea.

Several factors were in evidence in nations that adopted computing most extensively the quickest, while a number of environmental issues conversely slowed diffusion. In support of diffusion, one has to begin with the military investments in Cold War ICT, which many scholars have already studied. In the pan-Atlantic community, however, we must also recognize the legal protections provided for contracts and patents, because these protections for vendors facilitated development and sale of ICTs. All over the world, those nations that allowed the free flow of information did well. Having a capitalist economy helped enormously by providing economic incentives for innovation and risk taking, and for making available investment capital. Another economic factor was the availability of stable currencies and private sector venture capitalists, the first for cash liquidity and the second for competent investment and managerial "know-how." The existence of technical universities, institutes and academies populated with engineers, scientists, mathematicians, and individuals interested in practical construction of ICT and their use was and continues to be essential to diffusion. Finally, and very importantly, having public policies that promoted the diffusion of computing proved to be as crucial as the military investments.

We now also know there existed practices and circumstances that slowed the rate and extent of diffusion of ICT in the twentieth century, with many of the lessons coming from behind the Iron Curtain. These included secrecy in public administration and related to that lack of accurate information or inadequate free flow of knowledge, particularly among potential users, but, also to some extent, for computer builders and programmers. Centralized communist economic planning and control created havoc in the supply chains of whole industries and nations, particularly if these led to incentives that discouraged innovation or reduced the hunt for economic productivity - a major problem across all of communist dominated Central and Eastern Europe from the 1950s through the 1980s, and still a lingering 
heritage in contemporary Russia. Lack of contract and patent protection slowed innovation and adoptions. Just as educated people were needed to develop ICTs and then to use them, so too weak educational programs and inadequate technical human resources proved harmful. Regarding infrastructures, good telephone networks and adequate supplies of electricity were needed for the "I" and the "C" of ICT as well. In short, ICTs needed a broad, complex and supportive eco-system to flourish comprised of technological, scientific, economic, political, social and educational infrastructures.

A few surprises also emerged from the country-level research that one would do well to take into account in future studies of ICT, three in particular because they have global implications. First, technological and economic effects of Moore's Law were only marginally important in promoting diffusion and innovation, surprising because economists have maintained for decades that it was paramount in diffusion. The Law was - and continues to be-most important to North Americans and South Koreans in their highly competitive economies and ICT industries and de rigueur in the semiconductor industry. It proved of no consequence in the USSR where it was routine to use ten to fifteen year-old technologies regardless of their cost of operation or lost opportunities for improved operational productivity. Many West European, American, and Japanese users knew ICT was very costly in the 1950s through the 1970s; however, they incurred most of their expenses for software and in programming and staff needs.

Second, national initiatives to upgrade and improve telecommunications taught policy makers how they thought they should manage national champions and ICT diffusion as well. For example, their generally positive experience with telecommunications profoundly influenced French regulators and political leaders. On the other hand, Central Europeans and the Russians had poor telecommunications networks, which they never fixed properly by replacing older ones with more modern systems that could handle voice and data at greater volumes and quality or by diffusing sufficiently ICT throughout an economy during the entire period of communist rule. These necessary changes only began in earnest during the early 1990s. Poor telecommunications constrained adoption of online computing and later use of the internet and other networks. Most developing economies in the 1990s and 2000s turned first to modernizing their telecommunications infrastructures before launching campaigns to increase the diffusion of computing.

Third, smaller countries often proved more agile in adopting ICT. These included all the Nordics, Netherlands, Belgium, Canada, Singapore, Latvia, and Costa Rica as examples. Not all small countries were so effective; for example, Trinidad \& Tobago, Venezuela, and Greece reinforce my major finding that multiple factors in combination influenced diffusion of ICT when they played either positive or negative roles.

Historians of all kinds of technologies are enamored with the special roles played by parties with a direct material interest in a technology such as programmers and hardware vendors in IT. So, what influence did they have on the spread of computing? It turns out that in every country, they played a very important role and we should study them in considerable detail. Advocates included all manner of IT professionals, vendors, sociologists, and other social commentators discussing telematic societies and end users with interest in ICT or in need of such technologies. 
American, Dutch, Danish and Swedish experiences demonstrated that internal IT advocates, local culture, and organization of specific institutions influenced profoundly the kinds of ICTs and rates of adoption they achieved. Centralized institutions were attracted to large computers, while decentralized organizations favored mini- and distributed systems. International firms exported ICT to their offices and factories in other countries, regardless of local practices, stimulating regional diffusions of ICT knowledge and uses. ICT vendors and their collaborators played important roles in shaping governmental initiatives and public opinion about the value of the technology, both often collaborating with business partners and the press in discussing computing's role and value, usually in very positive terms. Commentators about the future of society originally came from academies and universities in the 1950s and 1960s; then the media and business commentators joined them in the 1970s and 1980s, but only in the most advanced economies.

The top third of all OECD countries were early and extensive adopters, as measured by per capita GDP, beginning in the early 1950s. The second tier were seven to ten years behind in rates of adoption (began in the early 1960s) while the bottom one third were the late adopters, most beginning in the 1980s. Economies with large companies and agencies were early and continuing adopters surpassing those nations that had smaller institutions, regardless of land mass and population size such as the very large and extensively populated Western Russia, Eastern China and all regions of Italy, which were technological laggards.

All various data points lead to several fundamental conclusions that could alter our perception of the broad issue of computing's diffusion. First, technology alone seemed to play a less influential role in diffusion than did other factors such as political issues and availability of information, skills and funding. Second, historians need to de-emphasize - but not ignore-features and costs of a particular device or software in general and instead increase their focus on how a technology was used in different industries, organizations, and cultures; so, the history of applications must be studied in considerable detail, as is already beginning to happen.

Third, the world went through one major wave of diffusion so far but also a second wave also seems to have started in many countries, typically in all top tier OECD nations and many smaller states in second tier countries. We will come back to the definition of the waves later. The notion that the world has just finished its first round of diffusion of IT suggests that we should de-emphasize old notions of hardware generations in describing ICT eras if for no other reason than multiple generations of equipment were in simultaneous use in all countries. We should become cautious about generalized rules of ICT and economic behavior in characterizing patterns of behavior, such as an over reliance on Moore's Law, but not discard them, and in particular, emerging rules and insights about the behavior of users and networks. We must pay more attention to economic literature on diffusion of ICT to understand fundamental motivations and practices concerning adoption of technologies. Yet, looking at technologies themselves can conveniently help differentiate between first and second waves of computing. Hence, we should not be absolute in our conclusions.

Fourth, as we look at the role of ICT in any society, we should realize that the subject cannot be discussed outside the context of the national events and culture of the day. The days of just writing about specific ICTs, or of their industries, with 
minimal attention to political, social, cultural, economic, and business issues must end. I found ICTs a central feature of modern societies, and that was not an observation of just the period involving the internet. A number of years ago Paul Edwards made that obvious in his book dealing with the role of computing and the Cold War, dating it as far back as the 1950s [6]. In an extreme case, one can conclude after examining the role of ICT and IT politics in East Germany that one of the reasons this country's government failed was due to its poor management of IT. Additionally, today we also know that IT's importance to East Germany was one of the reasons why the Berlin wall went up in the first place, namely, to keep computer experts from leaving the country along with other technically skilled workers and scientists [7].

\section{The Role of Historic Waves in Information Technologies}

If we discard the old IT paradigm of defining computer eras by the generations of hardware and software introduced by IT vendors and, instead, define periods by a more comprehensive results-centered approach as historians do for other technologies, then we are given the opportunity to organize information about computing in new ways. For example, I have concluded that between roughly 1940 and 1990 or 1995 , the most economically endowed nations have gone through one era, not four or five in their use of computers. It is too early to give this one era a good descriptive name, so I propose an uncomfortable, unpolished temporary placeholder: Wave One. Eventually, someone will come up with a more elegant name such as was done for the Spanish Golden Age, the Napoleonic Era, or the Victorian Era. We need the placeholder because it appears that a Wave Two is underway that must be differentiated from the first as events will not wait for the historians to catch up.

So, what is Wave One all about? Wave One has several features. First, it relied very much on mainframe computers and their associated technologies with a particular emphasis on centralized computing as the dominant form of IT in those nations that used ICT. IT was embedded the most in the largest organizations in society and increasingly during Wave One in smaller organizations as more modular digital IT became more available such as in the forms of minicomputers, later personal computers, and then early telecommunications networks. During this wave, institutions were the dominant users of communication infrastructures linked to IT, and this happened during the second half of Wave One that evolved into ICT. ICT remained very expensive relative to other ways of processing options, but individuals began using computing at home and online such as with PCs. Because we are so close in time to Wave One - a wave still alive and emerging in dozens of countriesthe boundaries between it and Wave Two are not always evident-yet.

I am noticing the emergence of early features of Wave Two-again a placeholder of a name until someone can later define the era better. Wave Two already has some visible elements. First, it continues to do all the things users, vendors and societies did in Wave One, as those activities remain. Swedish government agencies still do the same data processing today as they did a few years ago, yet Sweden, for example, is clearly moving into Wave Two. However, new activities are integrated into those 
of Wave One, or are in addition to the earlier one such as a citizen accessing government services through mobile phones and websites that in prior years they did by filling out forms, making telephone calls, or by visiting a government office. A bigger difference is that individuals in Wave Two play a role almost equal economically to that of Wave One participants, who in the first wave were mostly managers that acquired and used IT on behalf of their enterprises and public agencies. In Wave Two economies, consumers spend almost as much as enterprises on such digital technologies as consumer electronics, and mobile communications, and own vast quantities of digital data they store in their phones, laptops, digital cameras, CDs, and DVDs. The percent of GDP spent by people on ICT approaches Wave One rates-it is no accident that Apple is prosperous-it evolved into a Wave Two enterprise, while Amazon.com and eBay were born into that new era.

In Wave Two whole societies begin to think and act as if they were telematic, networked cultures. Four behaviors seem to be in evidence. There is more discourse about the information age as present society or one soon to be. Manuel Castells publishes another book about telematic societies in Great Britain through Oxford University Press and knows that the largest number of readers of his book will be in those countries that are already extensive users of ICT, not in Central Africa or in Western China, where publications about telematic societies are virtually nonexistent. Another characteristic of Wave Two is more training of technical and knowledge workers, and labor that use brains more than brawn, resulting in extended economic activity coming from high-tech endowed products and services, and more knowledge work than before. IT is everywhere and digital, embedded in ever smaller forms and products, even in the air-wireless - and physically in almost all buildings, spaces inhabited by people, and on one's person in our pockets and sticking out of their ears. Wave Two is a time when bandwidth is something everyone "must have." In some countries it is seen as a citizen's entitlement as part of their legal and moral civil right to have access to information, for example Finland which recently passed a law making access to the internet a human right. The Finns were not alone in their views. A recent $\mathrm{BBC}$ poll reported that 87 percent of people in twenty-seven countries agreed with this idea [1]. Leaders of the eighteenth century French Enlightenment would be quite at home in Wave Two societies. Finally, one should note that Wave Two is coming in spurts and pieces, just as Wave One did and to such an extent that no clear global pattern is yet fully evident except mobile telephony, which is the most studied technological feature of Wave Two that we have today. Spurts and pieces of similarly repeated events and patterns explain why I use the word Wave. Finally, let us recognize that the study of mobile telephony will inform greatly the first generation of ICT historians who someday will describe Wave Two.

\section{How Should Students of ICT's History Proceed?}

This question can be answered with a list of questions - issues - that future historians can address. Waves One and Two are simply literary scaffolds to help get scholars to various parts and issues of IT's global history. I believe there are a few questions that we can start addressing to both waves. My list includes the following. 
- How did culture and politics of one nation affect use of computing in a broad region?

- To what extent is the country format I am using the best one for understanding the global history of ICT, or should we discard it in favor of some other model or models? What are these other models?

- How do we overcome the reluctance of scholars in one country to comment on the history of another? Lars Heide is willing to do that but will a Southern European be prepared to critique the digital history of Northern European nations, or Chinese digital history by a Japanese scholar?

- Since it appears that the Iron Curtain of the Cold War era was more like a chain link fence rather than some solid impenetrable barrier, what does ICT's history teach us about the economies, societies, and flow of information in communist Europe-an area as big and as populated as Western Europe. What does Cold War Eastern Europe teach us about the general movement of ICT knowledge globally to other communist regions, "Third World," "Unaligned Nations" of the twentieth century, and today's totalitarian societies?

- How do we overcome problems of so many languages to work with to build global histories of ICT themes? We all cannot be like the great twentieth century French historian, Fernand Braudel, who seemed comfortable working with so many languages.

- Finally, what can we do to build trans-national repositories of primary materials?

There are various actions we can take, however, that my limited study of global history of computing suggests are possible and useful. The collective experiences of the Nordics are additionally demonstrating how trans-national history collaboration is possible, engaging pioneers, users, scholars, and institutions. Let us use them as a laboratory in which to learn how to do well in other regions of the world. That means the Nordics are going to have to share more in English and in other languages how they are doing their histories of ICT, in particular the Swedes who currently seem to be the most advanced in the world in such collaborative work.

I ask Nordic scholars to write more in English because so few people in the world can read Swedish, Danish, Norwegian, or Finnish. Many speak and often write well in English or German. So for the Nordics and scholars in other countries, either write your histories in widely used languages or arrange for translations, not just translated summaries of your work. Otherwise your history will not be taken into account when writing global histories and your nation's accomplishments will remain marginalized as they normally have been in the past, denying scholars all over the world a fuller knowledge of the history of computing. Publishing in English proceedings of the Nordic computer history conferences is a wonderful example of what is possible. Without the first two volumes, many historians in other parts of the world would know almost nothing about the history of IT in northern Europe.

Just as Nordics were smart in how they used so many forms of ICTs, let us encourage them to help find solutions for reconstructing ICT's history of Central Europe. For a half century or more the archives of the communist countries were sealed from scholarly study, but now are open. We need historians to examine these, to reconstruct the history of 350 million people across all aspects of society, not just about computing. I believe this is one of the biggest research requirements for 
historians of all kinds for the next half century and certainly the biggest one for European history for at least several generations.

Write more national ICT histories in any language otherwise we Americans will continue to dominate the narrative. We need country histories of IT for almost all of Continental Europe, for each country in Latin America, for three-quarters of Asia, for a handful of nations in Africa, and for the entire Middle East. National histories are the bricks we need with which to build really good global histories of specific ICTs, uses, and themes.

Finally, continue encouraging the European Union and various national institutions to support pan-European ICT history and the development of pan-European ICT archival and history centers. As much as I love the Charles Babbage Institute in the middle of North America, if I were a European, I would have to say, "CBI is too far away from Stockholm, Paris or Helsinki."

Some final thoughts about global ICT trends are in order. ICT history is going global, because ICT is now used in every country, in almost all its current technological formats, by almost four billion people, soon by over five billion (largely cell phones). It is diffusing faster than the population of the world is growing. ICT is as important to understand within the histories of the late twentieth century, as are the political, business, economic and military events of the era. In short, ICT history is now mainstream. Yet, ICT is still emerging and changing, as it has not stabilized into some mature set of technologies, uses, or results and consequences. That continuing churn makes the work of historians very difficult. Finally, more than historians are interested in learning from the history of ICT - and the audience at this conference represents some of the best qualified people to assist in creating and using the insights of history to help them.

\section{References}

1. Economist Intelligence Unit: Digital Economy Rankings 2010: Beyond e-Readiness. EIU, London (2010)

2. Polastron, L.X.: The Great Digitalization and the Quest to Know Everything. Inner Traditions, Rochester, Vermont (2006)

3. Mounier-Kuhn, P.: L'informatique en France. PUPS, Paris (2010)

4. Heide, L.: Punched-Card Systems and the Early Information Explosion, 1880-1945. Johns Hopkins University Press, Baltimore (2009)

5. Misa, T.: Organizing the History of Computing: "Lessons Learned" at the Charles Babbage Institute. In: Impagliazzo, J., Järvi, T., Paju, P. (eds.) History of Nordic Computing, vol. 2. Springer, Berlin (2009)

6. Edwards, P.N.: The Closed World. MIT Press, Cambridge (1996)

7. Stokes, R.G.: Constructing Socialism: Technology and Change in East Germany, 19451990. Johns Hopkins University Press, Baltimore (2000) 